\title{
Distribución de bacterias potencialmente fijadoras de nitrógeno y su relación con parámetros fisicoquímicos en suelos con tres coberturas vegetales en el sur de la Amazonia colombiana
}

\author{
Andrea J. Mantilla-Paredes ${ }^{1}$, Gladys. I. Cardona ${ }^{1}$, Clara P. Peña-Venegas ${ }^{1}$, Uriel Murcia ${ }^{1}$, \\ Mariana Rodríguez ${ }^{2} \&$ Maria M. Zambrano ${ }^{2}$ \\ 1. Instituto Amazónico de Investigación Científica-SINCHI, Calle 20 No. 5-44, Bogotá DC, Colombia; \\ gcardona@sinchi.org.co \\ 2. Corporación Corpogen, Cra. 5 No 66A - 34, Bogotá DC, Colombia; mzambrano@corpogen.org
}

Recibido 02-IX-2008. C Corregido 22-II-2009. Aceptado 23-III-2009.

\begin{abstract}
Distribution of potentially nitrogen-fixing bacteria and its relationship with physicochemical parameters in soils with three vegetation types in the southern Colombian Amazon region. Potentially nitrogen-fixing microaerobic and aerobic bacteria were isolated from several Colombian Amazon soils (forest, pastures and chagras) and two landscapes (floodable and non floodable areas). The abundance and distribution of bacteria were evaluated, as well as their relationship with soil physical and chemical characteristics. Landscape had a direct influence on the abundance of the microaerobic bacteria, with higher numbers in forest and pasture soils in non-floodable zones. The aerobic isolates $(\mathrm{N}=51)$ were grouped into 19 morphologies, with the highest numbers found in forest soil in floodable zones. A higher number of aerobic morphologies was shared among forest sites (Nonmetric Multidimensional Scaling and Analysis of Similarity $\mathrm{p}<0.05$ ), and $40 \%$ of the distribution was explained by lime percentage and Al concentration. Rev. Biol. Trop. 57 (4): 915 927. Epub 2009 December 01.
\end{abstract}

Key words: nitrogen-fixing bacteria, amazon soil, floodable zone, non floodable zone, forest transformation.

El nitrógeno representa el $78 \%$ de los gases que componen la atmósfera; sin embargo esta fuente no se encuentra disponible para las plantas (Philippot \& Germon 2005). La principal fuente de este elemento para las plantas la constituye la materia orgánica del suelo (MOS), la cual es oxidada por los microorganismos del suelo para liberar el nitrógeno. Sin embargo en suelos con poca cantidad de MOS, este proceso no proporciona a los cultivos cantidades suficientes de nitrógeno inorgánico, por lo que la fijación de nitrógeno adquiere una gran importancia como fuente de nitrógeno adicional (Chotte et al. 2002).

La fijación biológica de nitrógeno provee la mayor fuente externa de nitrógeno para los diferentes ecosistemas. Este proceso es responsable del $65 \%$ de la fijación anual, mientras que los procesos industriales solamente representan el 25\% (Poly et al. 2001, Hamelin et al. 2002). La fijación biológica de nitrógeno se lleva a cabo exclusivamente por procariontes que tienen la capacidad de reducir el nitrógeno atmosférico $\mathrm{N}_{2}$, a amonio $\left(\mathrm{NH}_{4}\right)$, que puede ser utilizado por las plantas, contribuyendo a la mejora y productividad de los cultivos (Zehr et al. 2003, Philippot \& Germon 2005). Por tanto, cualquier deficiencia en los compuestos nitrogenados orgánicos e inorgánicos del suelo estimula la fijación microbiana de $\mathrm{N}_{2}$ (Rózycki et al. 1999). Varios estudios han demostrado la importancia y el efecto de la presencia de 
los microorganismos en procesos agrícolas, así como en el uso sostenible del suelo (Tengerdy \& Szakács 1998, Dey et al. 2004, Dillly et al. 2004, Kuiper et al. 2004).

En ecosistemas que dependen estrictamente del reciclaje de materia orgánica en descomposición, como es el caso de los suelos de la Amazonia (Peña-Venegas 2004), la fijación biológica de nitrógeno podría ser más significativa. Los suelos amazónicos son clasificados como Oxisoles y Ultisoles, los cuales representan el 34\% del total de esta clase de suelos a nivel mundial. Se estima que sólo en América Latina existen 800 millones de hectáreas de suelos con estas características que requieren de alternativas sostenibles de fertilización nitrogenada (Graham 1998).

Aunque una amplia variedad de bacterias fijadoras de nitrógeno han sido aisladas de la rizosfera de varios cultivos, hay un interés creciente en buscar nuevas cepas con cualidades especiales y que actúen eficientemente en suelos degradados. La identificación de bacterias con potencial para fijar nitrógeno provenientes de suelos amazónicos tendría ventajas comparativas con respecto a cepas fijadoras provenientes de otros ecosistemas, dada su capacidad natural para tolerar suelos ácidos de baja fertilidad y con altas concentraciones de aluminio. El presente trabajo es una contribución al desarrollo de alternativas sostenibles orientadas a aumentar la productividad de cultivos de importancia para la región.

\section{MATERIALES Y MÉTODOS}

Muestreo: La recolecta de suelos se realizó en julio y agosto de 2006, en tres coberturas diferentes del municipio de Leticia, Colombia (412'22.16" S, 6956'35.63" W): 1) bosques primarios poco intervenidos (ubicados en el Parque Nacional Natural Amacayacu y comunidad indígena de San Martín de Amacayacu); 2) pastizales en fincas privadas sobre la margen del río Amazonas y sobre la carretera LeticiaTarapacá; y 3) parcelas de máximo 5 ha de agricultura itinerante indígena, denominadas chagras, en dos resguardos indígenas. Cada cobertura se muestreó en dos tipos de paisaje: llanura inundable ó várzea (zonas de inundación periódica por el río Amazonas) y terrazas (zonas no inundables, de tierra firme). Las muestras de suelo se recolectaron siguiendo un diseño de muestreo sistemático (Corredor 2000), analizando seis repeticiones por tipo de cobertura (tres en cada paisaje) para un total de 18 unidades experimentales (UE). En cada UE se trazó una diagonal sobre la cual se ubicaron seis puntos espaciados $24 \mathrm{~m}$ entre sí; la muestra en cada punto se hizo a partir de una mezcla homogeneizada de cinco submuestras, tomadas cada una a $5 \mathrm{~m}$ alrededor del punto de referencia. Las muestras compuestas de los tres primeros puntos se homogenizaron en el laboratorio para tener una muestra (M1) y los tres últimos para tener una segunda muestra (M2) de cada UE, para un total de 36 muestras a analizar.

Una parte de cada muestra fue guardada para la determinación de las poblaciones de bacterias potencialmente fijadoras de nitrógeno y otra parte para análisis fisicoquímico. Las muestras fueron mantenidas en estas condiciones el menor tiempo posible hasta su procesamiento. Los análisis microbiológicos fueron realizados en los laboratorios del Instituto Sinchi en Bogotá y Leticia, mientras los análisis físicoquímicos en el laboratorio de suelos del Instituto Geográfico Agustín Codazzi (IGAC) en Bogotá.

Recuento de bacterias potencialmente fijadoras de nitrógeno: Se tomaron 10 $\mathrm{g}$ de suelo y raíces y se diluyeron en $90 \mathrm{ml}$ de solución salina al $0.85 \%$. Esta dilución $\left(10^{-1}\right)$ se incubó a $30^{\circ} \mathrm{C}$ durante $1 \mathrm{~h}$ en agitación constante a $3500 \mathrm{rpm}$. A partir de ésta se realizaron diluciones seriadas hasta obtener la dilución $10^{-5}$. Para el aislamiento de las bacterias microaerófilas, se utilizaron los medios de cultivo semisólidos (que permiten la movilización de estas bacterias hacia zonas con tensión de oxígeno) Nfb y JMV modificados, contenidos en frascos de vidrio con tapón de caucho con capacidad de $18 \mathrm{ml}$ y con $6 \mathrm{ml}$ de medio de cultivo, siguiendo la metodología de Weber (1999). La composición del medio 
$\mathrm{Nfb}$ fue la siguiente (pH:5.5): ácido málico: $3 \mathrm{~g} / \mathrm{l}$; glucosa: $2 \mathrm{~g} / \mathrm{l} ; \mathrm{K}_{2} \mathrm{HPO}_{4}$ : $5 \mathrm{ml}$ (sol.10\%); $\mathrm{MgSO}_{4} \cdot 7 \quad \mathrm{H}_{2} \mathrm{O}$ : $2 \mathrm{ml}$ (sol.10\%); $\mathrm{NaCl}: 1 \mathrm{ml}$ (sol.10\%); $\mathrm{CaCl}_{2} \cdot 2 \mathrm{H}_{2} \mathrm{O}$ : $2 \mathrm{ml}$ (sol.1\%); azul de bromotimol: $2 \mathrm{ml}(0.5 \%$ en $\mathrm{KOH} 0.2 \mathrm{~N})$; solución de micronutrientes: $2 \mathrm{ml}\left(\mathrm{Na}_{2} \mathrm{Mo}_{4} \cdot 2\right.$ $\mathrm{H}_{2} \mathrm{O}: 0.2 \mathrm{~g} / \mathrm{l} ; \mathrm{MnSO}_{4}: 0.235 \mathrm{~g} / \mathrm{l} ; \mathrm{H}_{3} \mathrm{BO}_{3}: 0.28 \mathrm{~g} / \mathrm{l}$; $\mathrm{CuSO}_{4} \cdot 5 \mathrm{H}_{2} \mathrm{O}: 0.008 \mathrm{~g} / \mathrm{l} ; \mathrm{ZnSO}_{4} \cdot 7 \mathrm{H}_{2} \mathrm{O}: 0.024$ g/l); EDTA-Fe: $4 \mathrm{ml}$ (sol 1.64\%); solución de vitaminas: $1 \mathrm{ml}$ (biotina: $0.1 \mathrm{~g} / 1$; piridoxal- $\mathrm{HCl}$ : $0.2 \mathrm{~g} / \mathrm{l}$ ); agar: $2 \mathrm{~g} / \mathrm{l}$. La composición del medio JMV (pH:4.5) fue: manitol: 3g/l; sacarosa: $2 \mathrm{~g} / \mathrm{l} ; \mathrm{K}_{2} \mathrm{HPO}_{4}: 2 \mathrm{ml}$ (sol.10\%); $\mathrm{KH}_{2} \mathrm{PO}_{4}: 15 \mathrm{ml}$ (sol.10\%); agar: $2.2 \mathrm{~g} / \mathrm{l}$; los demás componentes $\left(\mathrm{MgSO}_{4} \cdot 7 \mathrm{H}_{2} \mathrm{O}, \mathrm{NaCl}, \mathrm{CaCl}_{2} \cdot 2 \mathrm{H}_{2} \mathrm{O}\right.$, azul de bromotimol, solución de micronutrientes y solución de vitaminas) en iguales cantidades al medio Nfb. En la superficie de los medios de cultivo mencionados se inocularon $100 \mathrm{ul}$ de las diluciones $10^{-3}, 10^{-4}$ y $10^{-5}$ para los suelos de la cobertura de pastizal y de las diluciones $10^{-2}$, $10^{-3}$ y $10^{-4}$ para los suelos de las coberturas de bosque y chagra; cada dilución se montó por triplicado. Los frascos fueron incubados a $30^{\circ} \mathrm{C}$ por cinco días o hasta observar crecimiento y presencia de película. A partir de este momento se registraron los tubos con crecimiento como el número más probable (NMP)/g de suelo de bacterias microaerófilas potencialmente fijadoras de nitrógeno en cada frasco, dilución y medio de cultivo evaluado.

Para el aislamiento de las bacterias aerobias se sembraron $100 \mu 1$ de la dilución $10^{-4}$ en la superficie del medio de cultivo Ashby, con algunas modificaciones (Becking 2006), obteniendo una dilución final de $10^{-5}$. La composición del medio fue la siguiente ( $\mathrm{pH}: 5.8)$ : sacarosa: $5 \mathrm{~g} / \mathrm{l}$; glucosa: $5 \mathrm{~g} / \mathrm{l} ; \mathrm{KH}_{2} \mathrm{PO}_{4}$ : $0.2 \mathrm{~g} / \mathrm{l}$; $\mathrm{MgSO}_{4}: 0.2 \mathrm{~g} / \mathrm{l} ; \mathrm{NaCl}: 0.2 \mathrm{~g} / \mathrm{l} ; \mathrm{CaSO}_{4}: 0.2 \mathrm{~g} / \mathrm{l}$; $\mathrm{CaCO}_{3}$ : $5 \mathrm{~g} / \mathrm{l}$; agar: $15 \mathrm{~g} / 1$. Las muestras se sembraron por triplicado y se incubaron en posición invertida a $30^{\circ} \mathrm{C}$ por ocho días para determinar las unidades formadoras de colonia (UFC) $/ \mathrm{g}$ de suelo para cada una de las 36 muestras. Se realizó una descripción de características macroscópicas (color, tamaño, forma, elevación, consistencia) y microscópicas (forma y coloración de Gram) para cada aislamiento recuperado.

Análisis de datos: Para el análisis de los datos se utilizó el paquete estadístico Primer 5. Para explorar la similitud existente entre las coberturas y los paisajes con respecto a la presencia/ausencia de morfotipos se realizó un análisis NMDS mediante la aplicación del índice de similaridad de Bray Curtis con un total de 999 permutaciones. Los datos fisicoquímicos de los suelos muestreados se analizaron también con NMDS pero aplicando la medida de similaridad de distancia euclidea (Clarke \& Warwick 1982). Se llevó a cabo el análisis BIO-ENV (Clarke \& Ainsworth 1993) que permite determinar el conjunto de variables ambientales que explica mejor la distribución de los datos biológicos en el análisis de NMDS, utilizando múltiples correlaciones de Pearson por rangos.

\section{RESULTADOS}

Abundancia de bacterias potencialmente fijadoras de nitrógeno: El aislamiento de microorganismos en medios libres en nitrógeno, como Ashby, Nfb y JMV, constituye un primer paso hacia la identificación de bacterias con capacidad para fijar nitrógeno. Aunque esta actividad está en proceso de ser comprobada mediante el ensayo de reducción de acetileno (Park et al. 2005) en el laboratorio, el análisis del número y tipo de microorganismos identificados en estos medios brinda información valiosa acerca de la distribución de microorganismos potencialmente fijadores de nitrógeno en los diferentes sitios muestreados. Los resultados muestran que los suelos bajo terraza en la cobertura de pastizal $\left(8.42 \times 10^{2} \mathrm{NMP} / \mathrm{g}\right.$ de suelo) presentan los mayores recuentos de bacterias microaerófilas seguido por la cobertura de bosque $\left(7.57 \times 10^{2} \mathrm{NMP} / \mathrm{g}\right.$ de suelo) y finalmente chagra bajo los dos paisajes (2.2 y $2.62 \times 10^{2} \mathrm{NMP} / \mathrm{g}$ de suelo) (Fig. 1A). Se encontraron diferencias importantes al comparar la recuperación de bacterias microaerófilas en los medios de cultivo JMV y Nfb. En el medio JMV se encontró un mayor número de 

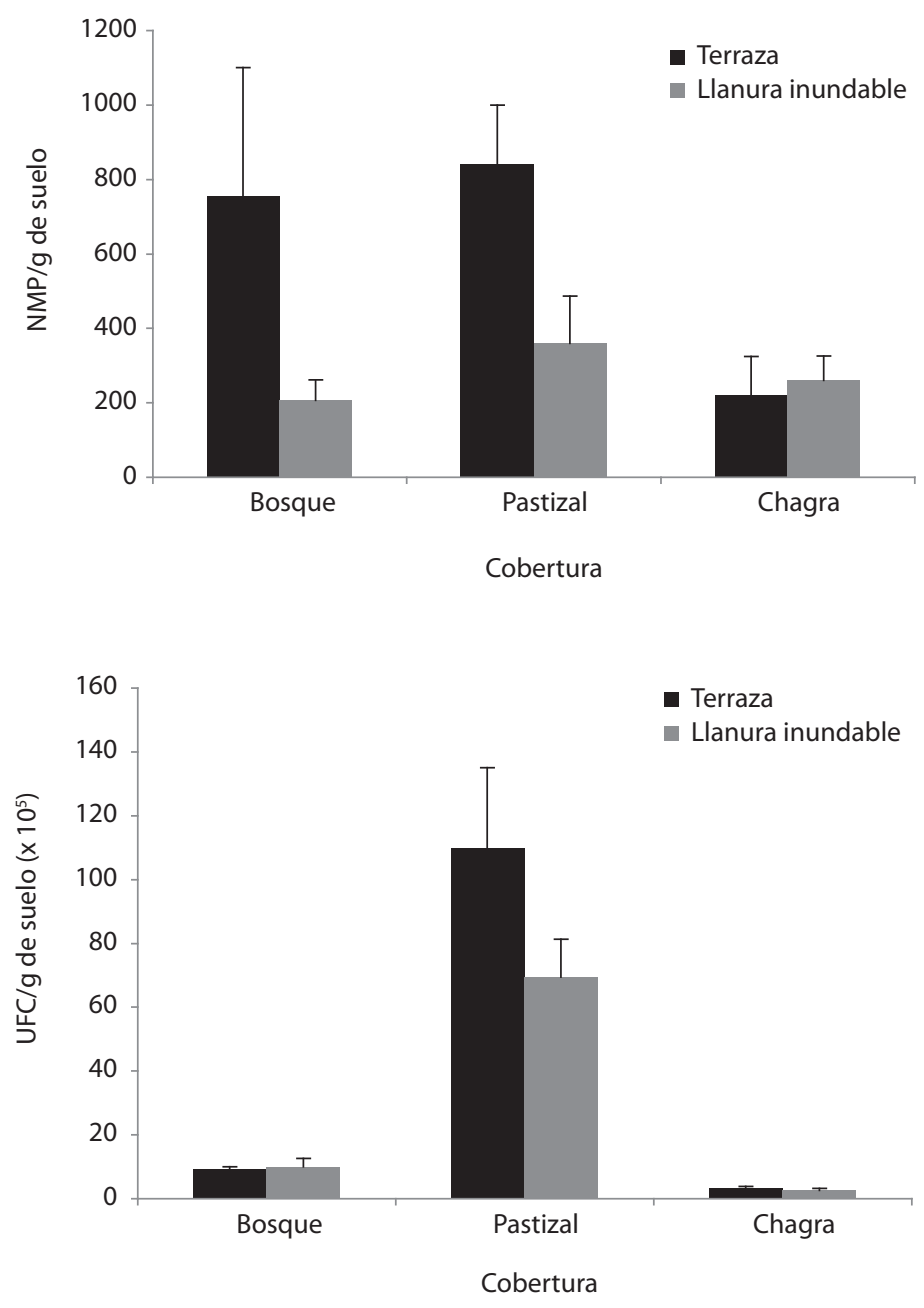

Fig. 1. (A) Abundancia de bacterias microaerófilas con potencial fijador de nitrógeno ( $\mathrm{NMP} / \mathrm{g}$ de suelo) en suelo rizosférico bajo coberturas de bosque, pastizal y chagra en paisajes de terraza y llanura inundable. (B) Abundancia (x $10^{5}$ UFC/g de suelo) de bacterias aerobias con potencial fijador de nitrógeno en suelos rizosféricos bajo coberturas de bosque, pastizal y chagra en paisajes de terraza y llanura inundable.

Fig. 1. (A) Abundance of potential nitrogen fixing microerobic bacteria (MPN/g of soil) in rhizospheric soil under forest, pasture and chagra in the floodable and non floodable zones. (B) Abundance (x $10^{5} \mathrm{CFU} / \mathrm{g}$ soil) of potential nitrogen fixing aerobic bacteria under rhizospheric soil present in forest, pasture and chagra in the floodable and nonfloodable zones.

bacterias para el paisaje de terraza con respecto al medio $\mathrm{Nfb}$, el cual reportó mayores recuentos en el paisaje de llanura inundable (Cuadro 1).

En relación a la abundancia de bacterias aerobias, los suelos bajo pastizal reportaron los recuentos más altos (7 y $11 \times 10^{6} \mathrm{UFC} / \mathrm{g}$ de suelo), seguido por los suelos bajo bosque (9.39 y $10 \times 10^{5} \mathrm{UFC} / \mathrm{g}$ de suelo) y finalmente los suelos bajo chagra (2.93 y $3.2 \times 10^{5} \mathrm{UFC} / \mathrm{g}$ de suelo). Respecto al paisaje al interior de cada cobertura, los suelos bajo terraza en pastizal (11x106 UFC/g de suelo) reportaron los valores más altos (Fig. 1B). 
CUADRO 1

Abundancia de bacterias microaerófilas con potencial fijador de nitrógeno presentes en las coberturas evaluadas, aisladas en los medios de cultivo JMV y Nfb

TABLE 1

Abundance of potential nitrogen fixing microaerophilic bacteria present in the evaluated soil types, isolated on JMV and Nfb media

\begin{tabular}{|c|c|c|c|}
\hline \multicolumn{2}{|c|}{ Sitios de muestreo } & \multirow{2}{*}{$\begin{array}{c}\text { Medio de cultivo JMV } \\
\text { Promedio (NMP/g de suelo) }\end{array}$} & \multirow{2}{*}{$\begin{array}{c}\text { Medio de cultivo Nfb } \\
\text { Promedio (NMP/g de suelo) }\end{array}$} \\
\hline Cobertura & Paisaje & & \\
\hline \multirow{2}{*}{ Bosque } & Terraza & $1100 \pm 0.00$ & $414 \pm 1.96$ \\
\hline & Llanura inundable & $151 \pm 0.48$ & $262 \pm 1.67$ \\
\hline \multirow{2}{*}{ Pastizal } & Terraza & $953 \pm 5.0$ & $732 \pm 2.68$ \\
\hline & Llanura inundable & $270 \pm 0.61$ & $450 \pm 1.16$ \\
\hline \multirow{2}{*}{ Chagra } & Terraza & $294 \pm 1.4$ & $146 \pm 0.44$ \\
\hline & Llanura inundable & $215 \pm 1.9$ & $306 \pm 1.46$ \\
\hline
\end{tabular}

Distribución de morfologías de aislamientos aerobios y su relación con las variables fisicoquímicas del suelo: Inicialmente se recuperaron 232 aislamientos primarios de bacterias aerobias con potencial para fijar nitrógeno, los cuales fueron agrupados en 19 morfologías de acuerdo a las características macroscópicas. Al determinar la frecuencia de cada morfología aislada se observó que los bosques albergaron la mayoría de estas morfologías, seguidos por las chagras y pastizales (Fig. 2). Igualmente, se observaron diferencias entre los paisajes evaluados, con mayor número de morfologías identificadas en los suelos de la llanura inundable, que en los suelos de terraza. Las morfologías macroscópicas que predominaron fueron: colonias blancas, traslúcidas, amarillas, cafés y grises, redondas y de bordes irregulares, pequeñas y medianas, planas y elevadas, brillantes y cerosas de esporulación rosada, blanca y café. Microscópicamente se observaron bacilos Gramnegativos cortos, delgados y largos, y cocobacilos Gramvariables y Grampositivos formando redes. Sin embargo,

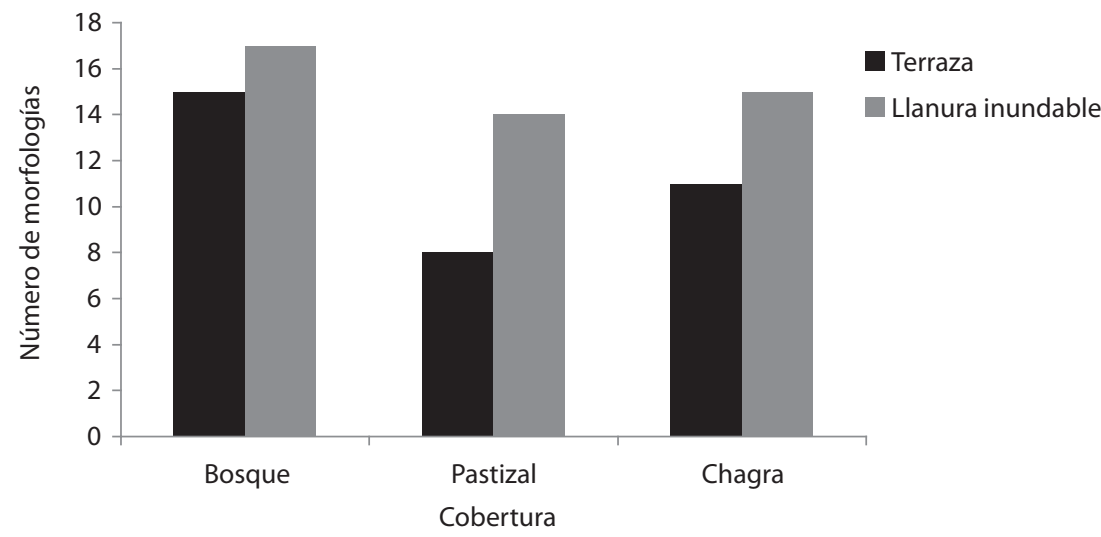

Fig. 2. Número de morfologías de aislamientos aerobios encontradas en cada una de las coberturas evaluadas.

Fig. 2. Number of morphologies of the aerobic isolates found in each soil evaluated. 
luego del repique secundario se recuperaron solamente 51 aislamientos igualmente agrupados en 19 morfologías, que se usaron para llevar a cabo los análisis de distribución en los diferentes sitios de muestreo y ensayos de reducción de acetileno (ARA) para determinar la actividad de la enzima nitrogenasa (datos no mostrados). Es importante anotar que la descripción morfológica no se utilizó para analizar especies o diversidad, puesto que no es un criterio útil para este propósito, sino para distinguir fácilmente los aislados y analizar su distribución.

El análisis NMDS, que se utilizó para explorar la relación entre coberturas y paisajes y la presencia/ausencia de morfotipos, mostró que existen diferencias significativas entre coberturas y entre paisajes (ANOSIM $\mathrm{p}<0.05$ ). En la Fig. 3 se observan los agrupamientos y las tendencias resultantes, en donde una mayor dispersión de los puntos (cada punto corresponde a una réplica o sitio de muestreo) al interior de cada cobertura indica que se comparten menos morfologías entre sus réplicas.

En la Fig. 3A se observa que al interior de la cobertura de bosque hay un mayor número de morfologías comunes entre los sitios muestreados que en chagra y pastizal, siendo ésta última la más disímil. Por otro lado, los paisajes no parecen relacionarse con la distribución de las morfologías descritas (Fig. 3B). Esto indica que las morfologías identificadas se agrupan según la cobertura pero no de acuerdo al tipo de paisaje.

Mediante el análisis BIO-ENV se determinó la relación existente entre las características fisicoquímicas del suelo (Cuadro 2) con la distribución de morfotipos de bacterias aerobias potencialmente fijadoras de nitrógeno. Se encontró que las variables que mejor explican la distribución espacial de las morfologías en una proporción relativamente baja $(\mathrm{p}=0.406)$ son: $\%$ limo y Al (meq/100g) (Fig. 4). En este análisis el tamaño de la burbuja indica el grado de representatividad que tiene una variable para explicar la distribución y dispersión de los sitios de muestreo respecto a las morfologías encontradas.

En la Fig. 4A se observa que los suelos bajo bosque se encuentran más agrupados con relación a la presencia/ausencia de morfologías y esto se relaciona con los valores encontrados para la textura (\% Limo), los cuales fueron muy similares entre las réplicas muestreadas bajo esta cobertura (desviación estándar baja, Cuadro 2). Esta similitud explica por lo tanto que se compartan mayor número de morfologías entre los diferentes sitios de muestreo de la cobertura de bosque.

CUADRO 2

Características fisicoquímicas de los sitios muestreados

TABLE 2

Physicochemical characteristics of the sampled sites

\begin{tabular}{|c|c|c|c|c|c|c|c|c|c|c|}
\hline Sitio & & o de suelo $(\%$ & & $\begin{array}{c}\text { R. } \\
\text { Penetrabilidad } \\
\text { (N/hora) }\end{array}$ & $\mathrm{pH}$ & $\begin{array}{c}\text { CIC } \\
\text { (meq/100g) }\end{array}$ & $\% \mathrm{CO}$ & $\% \mathrm{NT}$ & $\% \mathrm{SB}$ & $\begin{array}{c}\mathrm{Al} \\
(\mathrm{meq} / 100 \mathrm{~g})\end{array}$ \\
\hline & Arena & Limo & Arcilla & & & & & & & \\
\hline $\mathrm{BI}$ & $30.6 \pm 1.1$ & $13.8 \pm 1.2$ & $55.7 \pm 0.1$ & $32.08 \pm 6.98$ & $3.6 \pm 0.1$ & $35.5 \pm 4.6$ & $4.8 \pm 1.6$ & $0.5 \pm 0.1$ & $3.0 \pm 0.4$ & $19.37 \pm 1.53$ \\
\hline BT & $22.6 \pm 9.0$ & $44.1 \pm 4.2$ & $33.2 \pm 8.2$ & $37.33 \pm 6.7$ & $4.0 \pm 0.4$ & $21.8 \pm 6.8$ & $2.3 \pm 2.2$ & $0.2 \pm 0.2$ & $6.9 \pm 3.6$ & $8.33 \pm 1.7$ \\
\hline PI & $21.1 \pm 4.1$ & $55.3 \pm 8.0$ & $23.6 \pm 5.2$ & $104.75 \pm 56.34$ & $5.2 \pm 1.5$ & $16.5 \pm 1.2$ & $1.3 \pm 0.5$ & $0.1 \pm 0.05$ & $64.2 \pm 39.4$ & $2.93 \pm 3.78$ \\
\hline PT & $39.8 \pm 8.5$ & $33.1 \pm 8.6$ & $27.0 \pm 1.3$ & $78.42 \pm 14.32$ & $3.9 \pm 0.1$ & $17.8 \pm 2.9$ & $2.3 \pm 0.7$ & $2.3 \pm 0.1$ & $22.5 \pm 14.7$ & $5.2 \pm 1.77$ \\
\hline $\mathrm{CHI}$ & $25.9 \pm 9.7$ & $16.1 \pm 3.2$ & $58.0 \pm 7.3$ & $35.08 \pm 1.62$ & $4.0 \pm 0 . .2$ & $40.2 \pm 6.3$ & $4.0 \pm 1.4$ & $0.4 \pm 0.1$ & $11.5 \pm 8.0$ & $13.57 \pm 2.7$ \\
\hline $\mathrm{CHT}$ & $46.6 \pm 24.2$ & $28.7 \pm 11.0$ & $24.7 \pm 13.7$ & $24.1 \overline{7} \pm 7$ & $3.6 \pm 0.2$ & $12.6 \pm 4.3$ & $1.9 \pm 0.4$ & $0.2 \pm 0.0$ & $10.1 \pm 4.9$ & $5.87 \pm 3.24$ \\
\hline
\end{tabular}

B: Bosque; P: Pastizal; CH: Chagra; I: Llanura inundable; T: Terraza; CIC: Capacidad de Intercambio Catiónico; \%NT: \% Nitrógeno Total; \%SB: \% Saturación de Bases; Al: Aluminio. 

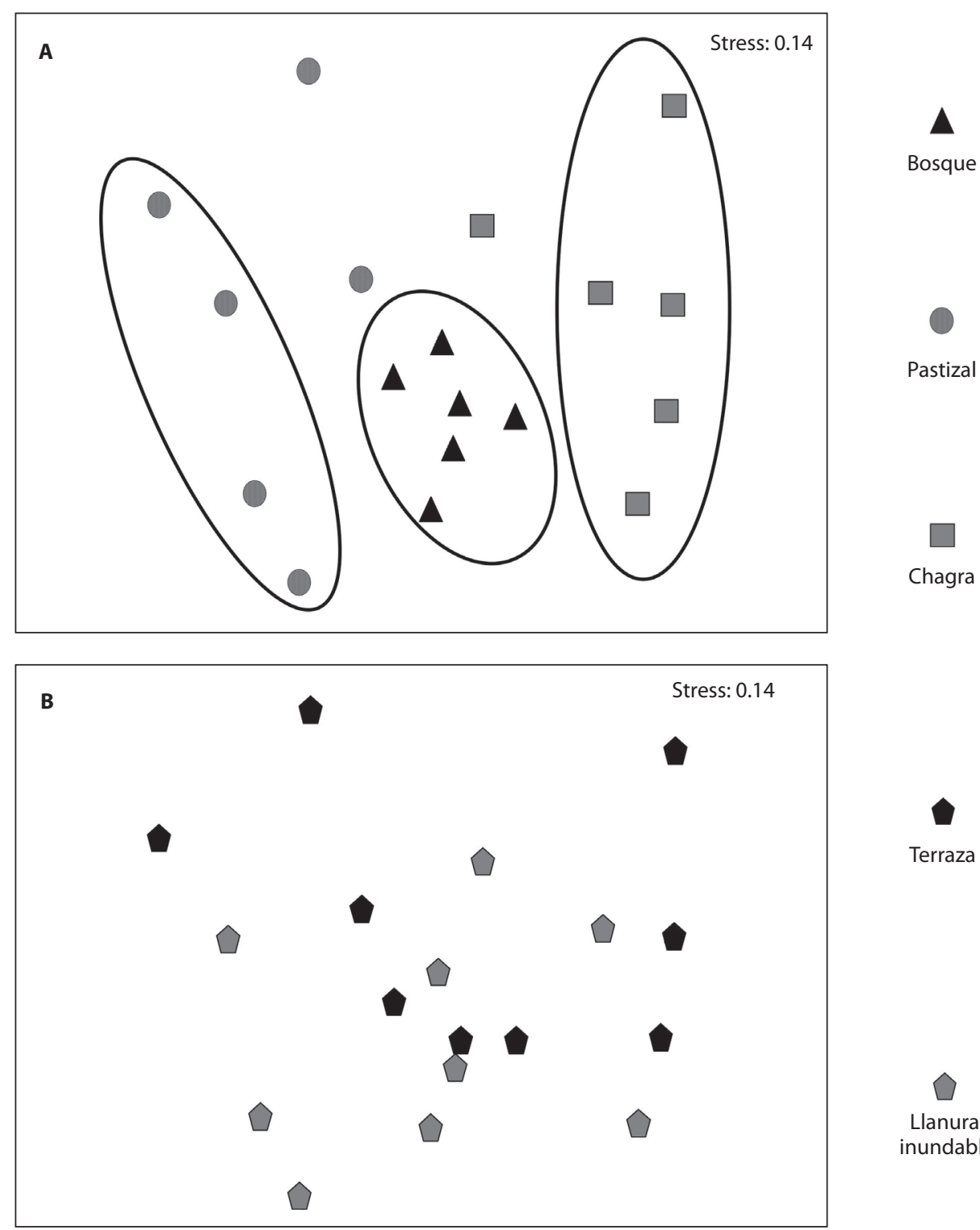

Terraza

Fig. 3. Análisis NMDS de las coberturas (A) y paisajes (B) evaluados con base en el número de morfologías.

Fig. 3. NMDS analysis based on soil use (A) and landscape (B) evaluated, based on the number of morphologies.

Por el contrario, se observa que la variable $\mathrm{Al}(\mathrm{meq} / 100 \mathrm{~g})$ explica, con una posibilidad del $40 \%$, la dispersión de los sitios de muestreo para la cobertura pastizal y posiblemente se relacione con un menor número de morfologías compartidas (Fig. 4B).

\section{DISCUSIÓN}

En este trabajo se realizó el aislamiento de microorganismos en medios libres de nitrógeno como un primer paso para la identificación y posterior análisis de bacterias potencialmente 

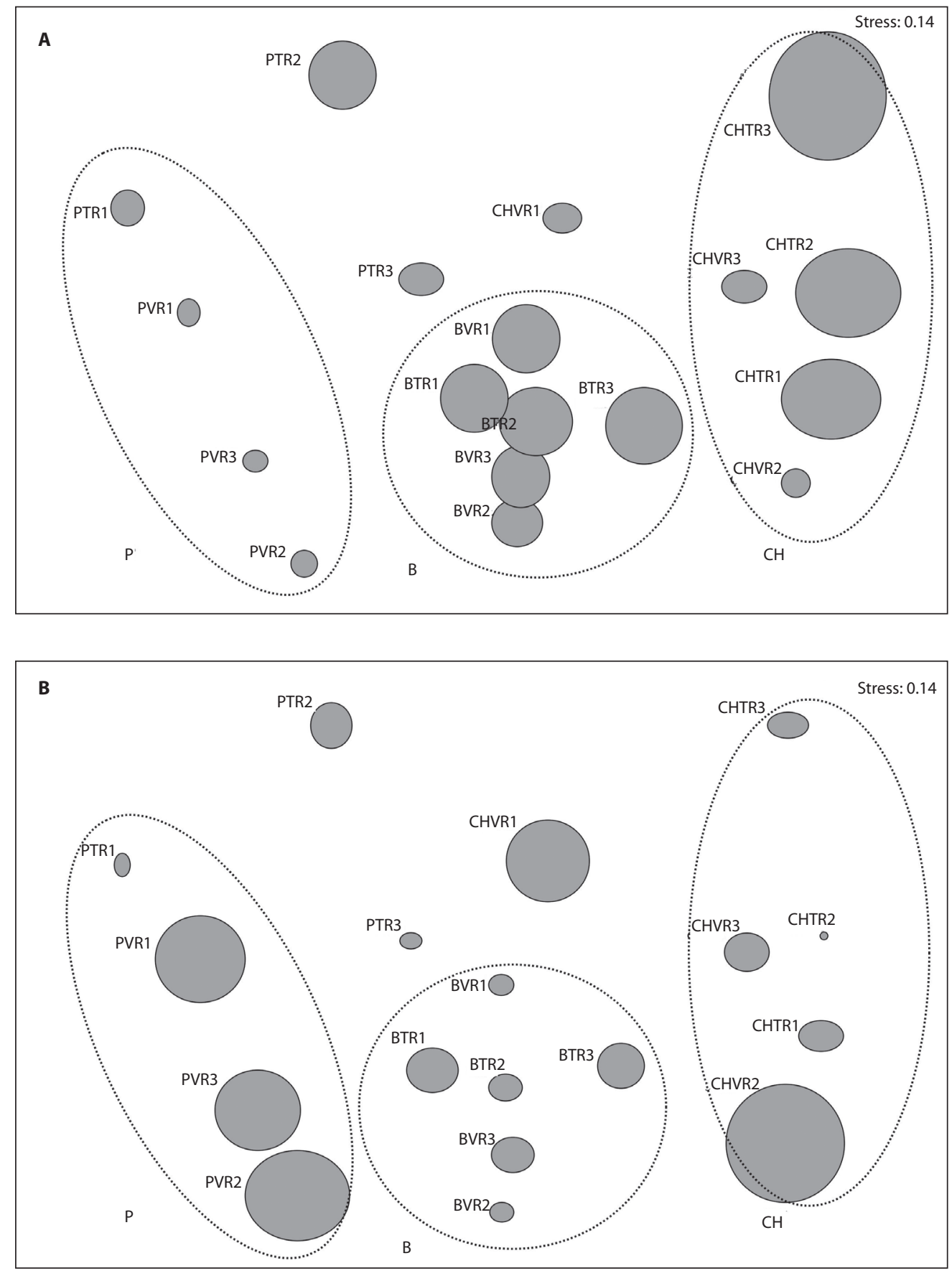

Fig. 4. Distribución de los sitios de muestreo-relación con las variables fisicoquímicas del suelo: (A) \% L y (B) Al (meq/100g) y la presencia/ausencia de morfologías. P: Pastizal, B: Bosque, CH: Chagra.

Fig. 4. Distribution of the sampled sites-relation with the physicochemical characteristic of soil: (A) \%L and (B) Al (meq/100g) and the presence/absence of the morphologies. P: Pasture, B: Forest, CH: Chagra. 
fijadoras de nitrógeno. De acuerdo a estos resultados se encontró una mayor recuperación de aislamientos primarios en suelos de pastizal, seguidos de bosques y finalmente de chagra. Este resultado es interesante porque contrasta con la mayor riqueza en vegetación que se encuentra en los bosques, y concuerda con hallazgos anteriores de bacterias diazótrofas en el interior y en la superficie de las raíces de varias gramíneas tropicales como es el caso de bacterias del género Azospirillum (Marín et al. 1998). Es posible, por consiguiente, que el cambio de vegetación, y en especial la presencia de gramíneas (Brachiaria sp.), pueda favorecer el establecimiento de bacterias aerobias y microaerófilas. Este tipo de gramínea mantiene un buen crecimiento radical a expensas del crecimiento de la parte aérea, puede adquirir nitrógeno mediante fijación asociativa (Dalton \& Kramer 2006), usa ambas formas de nitrógeno (nitrato y amonio) y, al igual que en otros suelos, toma fósforo y calcio mediante sistemas radicales extensos y asociaciones con micorrizas arbusculares (Rao et al. 1998). Gramíneas como Brachiaria tiene buena adaptabilidad a suelos ácidos de baja fertilidad como los presentes en el trópico (Rao et al. 1998) y proporcionan una buena cobertura al suelo, manteniendo una producción de follaje alta y deposición de grandes cantidades de hojarasca y raíces en descomposición que aumentan la materia orgánica del suelo, contribuyendo al establecimiento de una mayor biomasa microbiana (Boddey et al. 1998).

Los análisis fisicoquímicos (Cuadro 2) indican que los suelos bajo la cobertura de pastizal tuvieron los niveles más bajos de aluminio de cambio, el cual en altas concentraciones limita el crecimiento radicular de las plantas y está relacionado con la acidez de los suelos (Galeano 1990). Las prácticas agronómicas en estos pastizales, como la incorporación de abonos orgánicos y posiblemente calcio (Cardona 2004; datos no mostrados), aumentan la capacidad de intercambio de cationes y retención de éstos, evitando que muchos nutrientes se pierdan por el lavado (Galeano 1990). También se observó que el suelo bajo pastizal terraza se caracterizó por tener mayor concentración de carbono orgánico (Cuadro 2) y una mayor actividad de macrofauna (dato no mostrado). En conjunto estos factores podrían contribuir a una mayor dinámica de nutrientes por medio de la descomposición de la materia orgánica presente a formas más simples para efectos de su inmovilización y mineralización; de esta manera se da una mejor aireación en la capa superficial del suelo mejorando su estructura física (microambiente ideal para la colonización de bacterias aerobias potencialmente fijadoras) (Cardona 2004).

En contraste, los suelos bajo paisaje de llanura inundable, tanto en pastizal como bosques, sufren cambios en humedad por inundaciones periódicas que causan fluctuaciones en la rizosfera y en la disponibilidad de nutrientes, estructura del suelo y abundancia de los microorganismos presentes en este tipo de ecosistemas (Dalton \& Kramer 2006). En el caso de pastizal y bosque, estas fluctuaciones resultaron en menores valores de abundancia en general, mientras que para la chagra, y particularmente para bacterias microaerófilas (Fig. 1A), ocurrió lo contrario. Esto podría explicarse por los valores altos de nitrógeno total registrados (Cuadro 2) que podrían afectar el establecimiento de estas bacterias y estimular la presencia de otras poblaciones microbianas.

En la cobertura de bosque se encontró una menor abundancia de bacterias aerobias y microaerófilas con potencial para fijar nitrógeno con respecto a la cobertura de pastizal. Los bosques se caracterizan por tener una mayor diversidad de especies vegetales (dato no mostrado) y un movimiento continuo de nutrientes, debido a que albergan gran variedad de microhábitats con diversos sustratos y acumulación alta y permanente de residuos de diversas especies vegetales (como no ocurre en la cobertura de pastizal y en mucho menor grado en chagra), como carbono, que favorecen a microorganismos capaces de utilizar estas fuentes alternas de nutrientes más eficientemente que las bacterias diazótrofas (Torsvik et al. 1996). Cuando el bosque es talado y quemado para instalar pastizales (Uhl \& Jordan 1984, Matson et al. 
1987, Antón 1999), mueren muchos de los microorganismos presentes y parte del nitrógeno se volatiliza durante la quema (Holsher et al. 1997, Mackensen et al. 1999). En ausencia de fuentes externas importantes de nitrógeno la fijación de nitrógeno se convierte en una de las principales rutas para la recuperación del suelo (Gehring et al. 2005), por lo cual bacterias con capacidad para fijar el nitrógeno de la atmósfera pueden aumentar sus poblaciones al tener una ventaja competitiva y ocupar espacios que antes eran ocupados por otros grupos bacterianos que desaparecen (Peña-Venegas 2004, Cardona 2004).

Los suelos de chagra registraron los recuentos más bajos de bacterias aerobias y microaerófilas con potencial para fijar nitrógeno, lo cual puede estar relacionado con el proceso de transformación de la cobertura natural. Para el establecimiento de la chagra, se tala y quema el bosque y este incremento de la temperatura elimina indistintamente muchos de los microorganismos del suelo (Covaleda 1996). Peña-Venegas (2004) reportan que en chagras de menos de cuatro meses de establecidas se observó una baja presencia de esporas de micorrizas arbusculares comparado con otras coberturas, lo que sugiere que la red de micelio requiere de un lapso de tiempo mayor para establecerse. Este proceso de sucesión microbiana es seguido por actinomicetos, los cuales se han reportado como productores de sustancias antimicrobianas (Kitouni et al. 2005) que podrían inhibir el crecimiento de bacterias, entre éstas las fijadoras de nitrógeno. Finalmente, llegan otras bacterias a terminar de transformar bioquímicamente las moléculas residuales (Cardona 2004). Con base en esto, es posible que el proceso de establecimiento de las poblaciones bacterianas en estos suelos tome más tiempo y solamente se establezca eficazmente en cultivos de mayor edad, en los cuales la oferta de nutrientes sea más alta (Gehring et al. 2005).

Es interesante notar que la abundancia de bacterias microaerófilas con potencial para fijar nitrógeno fue mayor en el medio $\mathrm{Nfb}$ para muestras provenientes del paisaje de llanura inundable y lo contrario ocurrió para las muestras provenientes del paisaje terraza (Cuadro 1). Esto se puede explicar por los valores de $\mathrm{pH}$ menos ácidos presentes en llanura inundable, gracias a los residuos de materia orgánica que trae el río y que contribuyen a que estos suelos sean más alcalinos. El medio de cultivo $\mathrm{Nfb}$ tiene un $\mathrm{pH}$ ligeramente más alcalino que el de la mayoría de los suelos y por consiguiente puede favorecer el crecimiento de bacterias aisladas bajo el paisaje de llanura inundable. En contraste, el medio JMV tiene un pH más ácido que se aproxima al reportado para los suelos muestreados bajo paisaje de terraza (Cuadro 2).

Distribución de morfologías y su relación con las variables fisicoquímicas del suelo: El análisis de los aislamientos aerobios recuperados indicó que bajo la cobertura de bosque se recuperó un mayor número de morfologías, seguido por las coberturas de chagra y pastizal. Aunque la morfología de una colonia bacteriana no es suficiente para diferenciar entre especies o hacer un análisis de diversidad más exhaustivo, sí da una idea de la variedad de aislamientos presentes. En este caso fue interesante observar que a pesar de recuperar un mayor número de aislamientos primarios aerobios en pastizales, los aislamientos provenientes de bosques presentaron más diferencias morfológicas. Es posible que estos bosques, con baja intervención antrópica y con abundantes fuentes nutricionales, favorezcan el establecimiento y diversificación funcional de grupos de microorganismos. Esto contrasta con lo que sucede en ecosistemas intervenidos, donde especies microbianas con metabolismos fácilmente adaptables a condiciones nuevas (por procesos de sucesión luego de deforestaciones o quemas cuando se da el establecimiento de una chagra o para crear pastizales) se abren paso formando grupos funcionales específicos, disminuyendo de esta manera la gran diversidad de microorganismos presentes en estas coberturas (Escobar 2003). Esto es particularmente evidente en pastizales donde hay una cobertura vegetal más homogénea (gramíneas) 
que puede proveer una abundante aunque poco diversa fuente de recursos que aparentemente favorece el crecimiento de grupos más restringidos de microorganismos (Cardona 2004).

También se observan diferencias en el número de morfologías recuperadas en los paisajes evaluados; en suelos bajo llanura inundable se recuperaron más morfologías que en suelos bajo terraza (Fig. 2). Esto podría deberse al aporte de nutrientes, y posiblemente de bacterias, por los sedimentos arrastrados a las zonas inundables por el río en los periodos de inundación, favoreciendo así la diversificación microbiana.

El análisis NMDS (Fig. 3A) indicó que al interior de la cobertura de bosque se comparten más morfologías entre sus sitios de muestreo en comparación con el pastizal y la chagra. Es posible que las diferencias entre las réplicas de los sitios muestreados haya influído sobre la distribución de las morfologías puesto que los sitios muestreados bajo la cobertura de bosque fueron más homogéneos que los de las coberturas de pastizal y chagra. Para el caso específico de pastizal, las réplicas variaron con respecto a la actividad de mesofauna y número de cabezas de ganado y para el caso de las chagras, hubo variación en cuanto a la edad de estos terrenos (entre 10 meses y dos años) y las especies vegetales presentes (datos no mostrados).

El análisis NMDS también indicó que los paisajes no parecen relacionarse con la distribución de los morfotipos estudiados (Fig. 3B), probablemente debido a que tienen características más conservadas entre sí. En el caso de llanura inundable se trata de suelos que sufren constantes procesos de rejuvenecimiento de la capa superficial relacionado con el periodo de inundación por el río. Por otra parte, los suelos bajo terraza son más evolucionados y por tanto son suelos con características más constantes en el tiempo (IGAC 2007).

El análisis realizado durante esta investigación permite conocer la influencia que ejerce la transformación de la cobertura vegetal sobre la comunidad microbiana en suelos del sur del trapecio amazónico cuando se establece un pastizal y, en menor grado, la chagra. Los resultados muestran que bajo la cobertura de pastizal hubo valores mayores de abundancia de bacterias aerobias y microaerófilas, potencialmente fijadoras de nitrógeno, dado por las propiedades químicas del suelo bajo esta cobertura (niveles bajos de aluminio, mayor contenido de carbono orgánico) así como también la presencia de gramíneas. Igualmente, se observó una influencia importante del paisaje sobre la abundancia de las bacterias microaerófilas pues las inundaciones periódicas que se presentan en la llanura inundable ocasionan cambios en la disponibilidad de nutrientes y de oxígeno, lo cual afecta directamente la abundancia y estructura de las comunidades microbianas. Por consiguiente, estos suelos bajo zona inundable del río Amazonas sufren fluctuaciones en cuanto a nutrientes, bacterias y carga orgánica que permiten la diversificación microbiana. En contraste con los registros de abundancia, los bosques guardan mayor número de morfologías de bacterias aerobias con respecto a las otras coberturas evaluadas. La correlación entre morfologías y coberturas indicó también una mayor similitud entre los sitios de muestreo bajo la cobertura de bosque, lo cual puede ser un reflejo de que el bosque en pie, y por consiguiente sus suelos, sufren pocos cambios. Al analizar la distribución de los sitios de muestreo con respecto a la presencia/ausencia de morfologías y las variables fisicoquímicas del suelo, se concluyó que propiedades como textura (\% de limo) y concentración de $\mathrm{Al}$ (meq/100 g) explican la mayoría de los cambios encontrados al interior de cada cobertura.

\section{AGRADECIMIENTOS}

Esta investigación fue financiada con recursos de Colciencias (proyecto No. 657013-17760). Queremos agradecer a Paola Clavijo, Claudia Burbano, Augusto Mazorra y Mario William Coy por el apoyo presentado durante el muestreo. Igualmente queremos agradecer a las comunidades indígenas de los kilómetros 11 de la vía Leticia-Tarapacá y a la comunidad de San Martín de Amacayacu por permitirnos tomar las muestras de sus tierras y su colaboración 
prestada, así como a Corpoamazonia y Parques Nacionales Naturales quienes también ayudaron en la gestión y socialización de este proyecto. Sin todos ellos no hubiera sido posible la realización de este trabajo.

\section{RESUMEN}

Se evaluó la abundancia y distribución de bacterias microaerófilas y aerobias potencialmente fijadoras de nitrógeno aisladas a partir de suelos bajo coberturas de bosque, pastizal y chagra en dos paisajes, terraza y llanura inundable, en el sur de trapecio amazónico. Se relacionó el recuento en placa en el medio Ashby de estas bacterias aerobias con las características físicas y químicas del suelo. Se encontró mayor abundancia de bacterias aerobias y microaerofilas en suelos bajo cobertura de pastizal. Se observó influencia directa del paisaje sobre la abundancia de bacterias microaerófilas registrando mayores recuentos los suelos bajo terraza en las coberturas de bosque y pastizal. Los aislamientos aerobios obtenidos (51) se agruparon en 19 morfologías, de las cuales se obtuvo mayor número en suelos bajo bosque y en el paisaje de llanura inundable. A través del análisis multidimensional no métrico (NMDS) y análisis de similaridades (ANOSIM) $(\mathrm{p}<0.05)$ se comprobó que entre los sitios de muestreo bajo la cobertura de bosque se comparten mayor número de morfologías de bacterias aerobias que bajo las demás coberturas. El programa BIOENV indicó que esta distribución fue explicada en un $40 \%$ por las variables $\%$ limo y $\mathrm{Al}(\mathrm{meq} / 100 \mathrm{~g})$.

Palabras clave: bacterias fijadoras de nitrógeno, suelo amazónico, llanura inundable, terraza, transformación del bosque.

\section{REFERENCIAS}

Antón, D. 1999. Pasturas y praderas, p. 93-103. In Diversidad, Globalización y sabiduría de la naturaleza. IDRC/Piriguazu Ediciones, Montevideo, Uruguay.

Becking, J.H. 2006. The family Azotobacteraceae, p. 759-783. In M. Dworkin \& S. Falkow (eds.). The Prokaryotes: a handbook on the biology of bacteria. Springer, Nueva York, EEUU.

Boddey, R.M., I.M. Rao \& R.J.Thomas. 1998. Reciclaje de nutrimentos e impacto ambiental de las pasturas de Brachiaria. CIAT. Brachiaria: biología, agronomía y mejoramiento. Cali, Valle del Cauca, Colombia.

Chotte J.L., A. Schwartzmann., A. Bally \& L.J. Monrozier. 2002. Changes in bacterial communities and Azospirillum diversity in soil fractions of a tropical soil under 3 or 19 years of natural fallow. Soil Biol. \& Biochem. 34: 1083-1092.
Clarke, J. \& R. Warwick. 1982. A practical strategy for analyzing multispecies distribution Patterns. Mar. Ecol. Prog. Ser 8: 37-52.

Clarke K.R. \& M. Ainsworth. 1993. A method of linking multivariate community structure to environmental variables. Mar. Ecol. Prog. Ser. 92: 205-219.

Corredor, P. 2000. Estructura de la comunidad edáfica del género Streptomyces en bosques relictuales y agroecosistemas del Quindío (Andes Colombianos). Tesis de Biología, Universidad Nacional de Colombia, Colombia.

Cardona, G.I. 2004. Evaluación de la diversidad de actinomicetos en suelos bajo tres coberturas vegetales en el sur del trapecio amazónico colombiano. Tesis M.Sc, Pontificia Universidad Javeriana, Bogotá, DC, Colombia.

Covaleda-Velez, A. 1996. Caracterización de sistemas de producción agrícola y pecuario; uso y manejo de las tierras y su evaluación con fines múltiples, p. 9771071. In IGAC (ed.). Aspectos ambientales para el ordenamiento territorial del municipio de Mitú. Departamento del Vaupés, Bogotá DC, Colombia.

Dalton, D.A \& S. Kramer. 2006. Plant-Associated Bacteria, p. 105-130. In S. S. Gnanamanickam (ed.). Nitrogenfixing bacteria in non-legumes. Springer, Dordrecht, Holanda.

Dey, R., K.K. Pal, D.M. Bhatt \& S.M. Chauhan. 2004. Growth promotion and yield enhancement of peanut (Arachis hypogaea L.) by application of plant growthpromoting rhizobacteria. Microb. Res. 159: 371-394.

Dilly, O., J. Bloem., A. Vos \& J.C. Munch. 2004. Bacterial diversity in agricultural soils during litter decomposition. Appl. Environ. Microbiol. 70: 468-74.

Escobar, L.F. 2003. Efecto del sistema de uso del suelo sobre la abundancia de poblaciones nativas de rizobios en la microcuenca potrerillo, departamento del Cauca. Tesis de pregrado en Ecología, Pontificia Universidad Javeriana, Bogotá DC, Colombia.

Galeano, F. 1991. Capacidad de intercambio catiónico y aniónico. Bases de cambio y saturaciones. Fundamentos para la interpretación de análisis de suelos, plantas y aguas para riego. Sociedad Colombiana de la Ciencia del Suelo (ed.). Santa Fé de Bogotá, DC, Colombia.

Gehring, C., P.L.G. Vlek, L.A.G. de Souza \& M. Denich. 2005. Biological nitrogen fixation in secondary regrowth and mature rainforest of central Amazonia. Agricult. Ecosys. \& Environ. 111: 237-252.

Graham, P. 1998. Biological dinitrogen fixation: Symbiotic, p. 332-334. In D. Sylvia., J. Fuhrmann., P. 
Hartel \& D. Zuberer (eds.). Principles \& Applications of Soil Microbiology. Prentice Hall, Upper Saddle River, Nueva Jersey, EEUU.

Hamelin, J., N. Fromin, S. Tarnawski, S. Teyssier-Cuvelle \& M. Aragno. 2002. NifH gene diversity in the bacterial community associated with the rhizosphere of Molinia coerulea, an oligonitrophilic perennial grass. Environ. Microb. 4: 477-481.

Holscher, D., R.F. Moeller, M. Denich \& H. Folster. 1997. Nutrient input-output budget of shifting agriculture in eastern Amazonia. Nutr. Cycl. Agoecosyst. 47:49-57.

Instituto Geografico Agustin Codazzi (IGAC). 1997. Zonificación Ambiental para el Plan Modelo ColomboBrasilero (Eje Apaporis - Tabatinga: PAT). IGAC, Bogotá DC, Colombia.

Kitouni, M., A. Boudemagh, L. Oulmi, S. Reghioua F. Boughachiche, H. Zerizer, H. Hamdiken, A. Couble, D. Mouniee, A. Boulahrouf \& P. Boiron. 2005. Isolation of actinomycetes producing bioactive substances from water, soil and tree bark samples of the north-east of Algeria. J. Mycol. Med. 15: 45-51.

Kuiper, I., E.L. Lagendijk, G.V. Bloemberg \& B.J. Lugtenberg. 2004. Rhizoremediation: a beneficial plantmicrobe interaction. Mol. Plant Microbe Interact. 17: 6-15.

Mackensen, J., D. Holscher, R. Klinge \& H. Folster. 1996. Nutrient transfer to the atmosphere by burning of debris in eastern Amazonia. For. Ecol. Manage. 86:12-128.

Marin, V., V. Baldani, K. dos Santos-Teixeira \& J.I. Baldani. 1998. Fijación biológica de nitrógeno: bacterias fijadoras de nitrógeno de importancia para la agricultura tropical. EMBRAPA-AGROBIOLOGIA, Seropedica, Río de Janeiro, Brasil.

Matson, P.A., P.M. Vitousek, J.J. Ewel, M.J. Mazzarino \& G.P. Robertson. 1987. Nitrogen transformations following tropical forest felling and burning on a volcanic soil. Ecology 68: 491-502.

Park, M., C.H. Kim, J. Yang, H. Lee, W. Shin, S. Kim \& T. Sa. 2005. Isolation and characterization of diazotrophic growth promoting bacteria from rhizosphere of agricultural crops of Korea. Microb. Res. 160: 127-133.

Peña-Venegas, C.P. 2004. Ficha BPIN: mantenimiento de la fertilidad del suelo y generación de tecnologías para la recuperación de áreas degradas en la amazonía colombiana. Informe final anual, Instituto Sinchi, Leticia, Colombia.

Philippot, L. \& J.C. Germon. 2005. Contribution of bacterial to initial input and cycling of nitrogen in soils, p. 159-176. In Buscot, F., \& Varma, A. (eds.). Microorganisms in soils: roles in genesis and functions, Springer, Nueva York, EEUU.

Poly, F., L.J. Monrozier \& R. Bally. 2001. Improvement in the RFLP procedure for studying the diversity of nifH genes in communities of nitrogen fixers in soil. Res. Microb. 152: 95-103.

Rao, I.M., P.C. Kerridge \& M.C.M. Macedo. 1998. Requerimientos nutricionales y adaptación a los suelos ácidos de especies de Brachiaria. CIAT. Brachiaria: biología, agronomía y mejoramiento. Cali, Valle del Cauca, Colombia.

Rózycki, H., H. Dahm, E. Strzelczyk \& C.Y. Li. 1999. Diazotrophic bacteria in root-free soil and in the root zone of pine (Pinus sylvestris L.) and oak (Quercus robur L.). Appl. Soil Ecol. 12: 239 - 250.

Torsvik, V., R. Sorheim \& J. Goksoyr. 1996. Total bacterial diversity in soil and sediment communities-a review. J. Indust. Microbiol. 17: 170-178

Tengerdy, R.P. \& G. Szakacs. 1998. Perspectives in agrobiotechnology. J. Biotech. 11: 66:91-99.

Uhl, C. \& C.F. Jordan. 1984. Succession and nutrient dynamics following forest cutting and burning in Amazonia. Ecology 65: 1476-1490.

Weber, O.B., V.L.D. Baldani, K.R.S. Teixeira, G. Kirchhof, J.I. Baldani \& J. Dobereiner. 1999. Isolation and characterization of diazotrophic bacteria from banana and pineapple plants. Plant and Soil 210: 103-113.

Zehr, J.P., B.D. Jenkins, S.M. Short \& G.F. Steward. 2003. Nitrogenase gene diversity and microbial community structure: a cross-system comparison. Environ. Microbiol. 5: 539-554. 
